REVIEW

\title{
Physiology of sport rock climbing
}

\section{A W Sheel}

Br J Sports Med 2004;38:355-359. doi: 10.1136/bjsm.2003.008169

Rock climbing has increased in popularity as both a recreational physical activity and a competitive sport. Climbing is physiologically unique in requiring sustained and intermittent isometric forearm muscle contractions for upward propulsion. The determinants of climbing performance are not clear but may be attributed to trainable variables rather than specific anthropometric characteristics.

Correspondence to: Dr Sheel, University of British Columbia, School of Human Kinetics, 2106081 University Blvd, Vancouver V6T 1Z1, Canada; bill. sheel@ubc.ca

Accepted 30 September 2003
R ock climbing has increased in popularity in the last 15-20 years both as a recreational physical activity and as a competitive sport. Sport climbing is the branch of climbing in which the element of danger is reduced by preplacing protection points in the rock or indoor wall. Because the danger element is largely removed, the physical difficulty of each climb can be high. Falls are commonplace and are relatively safe. Competitive sport climbing is governed by the International Council for Competition Climbing (ICC) which is a constituent part of the International Union of Alpinist Associations (Union Internationale $\mathrm{d}^{\prime}$ Associations d'Alpinisme (UIAA)). The ICC is responsible for the administration and development of all aspects of the sport of international competition climbing, and the UIAA has been granted recognition by the International Olympic Committee as an intermember federation. There are several different types of climbing competitions: leading, bouldering, speed climbing, and ice climbing. For the purposes of this review, emphasis will be on studies of leading or top rope situations.

Leading competitions recreate the challenge facing outdoor sport climbers on indoor climbing walls. A climbing competition usually consists of a series of rounds. Each round progressively reduces the number of climbers and increases the difficulty of the route. Climbers are scored on the height that they achieve, and the routes are designed so that all but one fall before the top is reached. The purpose of having more than one round is to determine the competitor who can consistently perform well and to present a final round of roughly evenly matched climbers. Climbers must attempt the routes "on sight". This means that they have no previous knowledge of the moves they must make to progress between the holds, and may not watch any other competitors in their attempts. Top rope climbing is when the climber is attached to a safety rope, which is passed through fixed bolt anchors at the top of the climb and returned to a belayer at the start of the climb. This style of climbing is extremely safe, and the risk to the climber is minimised.

For climbers to gauge their performance and the difficulty of a climb, a system of climbing grades is used. Several different systems have been developed around the world. Table 1 presents a comparison. For the purposes of this review, we will refer to the rating of difficulty based on the commonly used Yosemite decimal scale (YDS). Technical rock climbs graded with this scale range from the easiest at 5.0 to 5.9; grades from 5.10 upward are further subdivided into a, b, c, and d. The current "maximum grade" is considered to be $5.15 \mathrm{~b}$. It is generally assumed that the increments of difficulty progress in a linear fashion-that is, 5.9, 5.10a, 5.10b, etc. However, there can be discrepancies depending on the steepness of terrain and size of hand and foot holds. Ratings are also dependent on the local area climbing traditions, the size or height of the climbers rating the climb, the degree to which the climb can be protected from long falls, and the type of rock. Published climbing studies have used terms to describe climbers such as "elite", ${ }^{2}$ "expert", ${ }^{3}$ and "experienced". ${ }^{4}$ Within the available literature there is considerable overlap between these designations. As such, this review will provide the specific climbing grade used in a given investigation.

It is difficult to quantify the number of people who participate in climbing activities. The best number of active climbers in the United States is about 300000 (Editor, Rock and Ice Climbing Magazine, personal communication). This is based on the dollars spent annually in the climbing market and number of shoes and ropes purchased. Few published data exist to quantify the number of climbers world wide, but it is reasonable to suggest that it is in the several million range. The recent surge of indoor climbing facilities and the use of rock climbing as a mode of physical activity has raised questions about the metabolic cost of this activity. In addition, the popularity of climbing as a competitive sporting pursuit has raised questions of ideal training regimens. Despite the increasing number of indoor facilities, widespread popularity of this sport, and the development of local, national, and international competitions, the physiological responses to climbing are not well defined. As such, the purpose of this review is to critically examine what is known about the physiology of climbing. Anthropometric variables and other factors that may be important in determining climbing performance are also discussed. 
Table 1 Approximation of how various climbing grading systems compare

\begin{tabular}{|c|c|c|c|c|}
\hline British & Australia & YDS & UIAA & French \\
\hline & 19 & $5.10 a$ & $\mathrm{VI+}$ & $6 a$ \\
\hline \multirow[t]{2}{*}{$5 c$} & $19 / 20$ & $5.10 \mathrm{~b}$ & VII- & $6 a+$ \\
\hline & 20 & $5.10 c$ & VII & $6 \mathrm{~b}$ \\
\hline \multirow[t]{2}{*}{$5 c+$} & 21 & $5.10 \mathrm{~d}$ & VII+ & $6 b+$ \\
\hline & $21 / 22$ & $5.11 a$ & VII+/VIII- & $6 c$ \\
\hline \multirow[t]{2}{*}{$6 a+$} & 22 & $5.11 \mathrm{~b} / \mathrm{c}$ & VIII- & $6 c+$ \\
\hline & 23 & $5.11 \mathrm{~d}$ & VIII & $7 a$ \\
\hline \multirow[t]{2}{*}{$6 b$} & 24 & $5.12 a$ & VIII/VIII+ & $7 a+$ \\
\hline & 25 & $5.12 \mathrm{~b}$ & VIII+ & $7 b$ \\
\hline \multirow{3}{*}{$6 b+$} & 26 & $5.12 c$ & IX- & $7 b+$ \\
\hline & 27 & $5.12 \mathrm{~d}$ & IX & $7 c$ \\
\hline & 28 & $5.13 a$ & $I X / I X+$ & $7 c+$ \\
\hline \multirow[t]{2}{*}{$6 c+$} & 29 & $5.13 \mathrm{~b}$ & $I X+$ & $8 a$ \\
\hline & 30 & $5.13 c$ & $x-$ & $8 a+$ \\
\hline \multirow[t]{2}{*}{$7 a$} & 31 & $5.13 d$ & $x$ & $8 b$ \\
\hline & 32 & $5.14 a$ & $x_{+}$ & $8 b+$ \\
\hline \multirow[t]{2}{*}{$7 a+$} & 33 & $5.14 \mathrm{~b}$ & XI- & $8 c$ \\
\hline & 34 & $5.14 \mathrm{c}$ & $\mathrm{XI}$ & $8 c+$ \\
\hline \multirow[t]{3}{*}{$7 b$} & 35 & $5.14 d$ & $\mathrm{XI}+$ & $9 a$ \\
\hline & 36 & $5.15 a$ & XII- & $9 a+$ \\
\hline & 37 & $5.15 b$ & XII & $9 b$ \\
\hline
\end{tabular}

YDS, Yosemite decimal system; UIAA, International Union of Alpinist Associations (Union Internationale d'Associations d'Alpinisme).

\section{PHYSIOLOGICAL RESPONSES TO CLIMBING Oxygen consumption}

The act of climbing typically involves sustained and intermittent forearm muscle contractions. ${ }^{5}$ There is probably a major role for the lower limbs for upward propulsion, ${ }^{6}$ although this has not been quantified. It is important to emphasise that those studies that have measured oxygen consumption $\left(\dot{\mathrm{V}}_{2}\right)$ during climbing have measured "whole body $\dot{\mathrm{V}}_{2}$ " at the mouth, and the relative contributions from the upper and lower body musculature have yet to be differentiated. The $\dot{\mathrm{VO}}_{2}$ associated with climbing has been measured during indoor climbing (leading and top roping) ${ }^{35-7}$ and while climbing on a specific climbing treadmill. ${ }^{2}{ }^{8}$ Table 2 summarises these studies. Billat et al showed in a small group $(\mathrm{n}=4)$ of "high level climbers" that climbing $\dot{\mathrm{V}}_{2}$ was 24.9 (1.2) $\mathrm{ml} / \mathrm{kg} / \mathrm{min}$, which corresponded to $45.6 \%$ of maximal treadmill $\dot{\mathrm{V}}_{2}$. Subjects were homogeneous in their performance level (7b, French system; table 1). Climbers were climbing at or near their maximum ability in this study, and subjects were familiar with the climbing routes. It was concluded that rock climbing does not require a significant contribution from aerobic metabolism based on the low $(45.6 \%)$ of treadmill $\dot{V}_{2}$ max used. In a separate study, Sheel et $a l^{6}$ showed that, with increasing levels of climbing difficulty, there is a rise in the fractional use of whole body $\dot{\mathrm{V}}_{2} \mathrm{MAX}$ in a group of competitive climbers (5.12a-5.14c; YDS). Climbers were assigned to routes that were standardised to their "personal best". One climb was considered "harder" and the other "easier". Harder was defined as the climber's maximum minus two full grades, and easier as maximum minus three full grades. $\dot{\mathrm{V}}_{2}$ was significantly higher during harder than easier climbing (51\% v 45\% of cycling $\dot{\mathrm{V}}_{2} \mathrm{MAX}$ respectively; fig 1 ). Climbers in this study were climbing below their maximum and yet they achieved about $51 \%(22.7 \mathrm{ml} / \mathrm{kg} / \mathrm{min})$ of their cycling $\dot{\mathrm{V}}_{2} \mathrm{MAX}$. These results disagree somewhat with the findings of Billat et al, ${ }^{5}$ as they suggest that, as climbing difficulty increases, there is an increased reliance on aerobic metabolism. It is possible that part of the difference between the two studies is attributable to the lower $\dot{\mathrm{V}}_{2} \mathrm{MAX}$ often achieved with cycling compared with treadmill testing. To date, these are the only studies that have sought to compare climbing $\dot{\mathrm{V}}_{2}$ values with measured-that is, not predicted values-treadmill or cycle ergometer values. Other studies that have measured $\dot{\mathrm{V}}_{2}$ during lead and top rope climbing support the concept that the average $\dot{\mathrm{V}}_{2}$ during difficult sport climbing is about $25 \mathrm{ml} / \mathrm{kg} / \mathrm{min}^{3}{ }^{7}$

Continuous climbing on a climbing treadmill (four minute bouts at angles of $80^{\circ}, 86^{\circ}, 91^{\circ}, 96^{\circ}$, and $102^{\circ}$ relative to vertical) elicited $\dot{\mathrm{V}}_{2}$ values of $31.3,31.7,31.2,29.5$, and $30.9 \mathrm{ml} / \mathrm{kg} / \mathrm{min}$ respectively. ${ }^{8}$ The lack of change in $\dot{\mathrm{V}}_{2}$ with increasing angle (and presumably difficulty) may be because arm specific peak $\dot{\mathrm{VO}}_{2}$ was attained or the differences between angles used in this study were too small to allow differentiation in $\dot{\mathrm{V}}_{2}$. The ability to climb greater angled and more difficult climbs was probably due to an increased reliance on anaerobic glycolysis. In a separate climbing treadmill study, Booth et $a^{2}$ had subjects perform a sport climbing specific test of maximal aerobic capacity where they climbed to volitional exhaustion. Maximal oxygen consumption during climbing was $43.8(2.2) \mathrm{ml} / \mathrm{kg} / \mathrm{min}$ in a group of intermediate/expert (6b-7a; French system) climbers.

In summary, from the available data, it appears that climbing requires use of a significant portion of whole body aerobic capacity. Increases in climbing difficulty, and climbing more steeply angled climbs, probably requires use of anaerobic energetic pathways (see below).

\section{Heart rate and blood pressure}

Heart rate increases as climbing difficulty increases. ${ }^{6}$ Reported values during climbing range from 129 to 180 beats/min. ${ }^{3569}$ The variability in heart rates may be attributed to different climbing intensities or climbing experience/skill level. ${ }^{9}$ Nevertheless, it is clear that heart rate increases during climbing efforts. Several studies have noted that there is a disproportional rise in heart rate compared with $\dot{\mathrm{V}}_{2}$ during climbing. ${ }^{2-8}$ During climbing, Billat et al ${ }^{5}$ found that climbers reach about $80 \%$ of their maximal heart rate for treadmill running and only $46 \%$ of maximal treadmill $\dot{\mathrm{V}}_{2}$. This is consistent with the work of Sheel et $a l^{6}$ who found that heart rate was $89 \%$ and $66 \%$ of maximal heart rate, and $\dot{\mathrm{V}}_{2}$ was $67 \%$ and $45 \%$ of $\dot{\mathrm{V}}_{2} \mathrm{MAX}$ for cycle exercise during harder and easier climbing respectively.

Why does heart rate rise out of proportion to $\dot{\mathrm{V}}_{2}$ during climbing? Because climbing requires repetitive isometric contractions of the forearm musculature, it is reasonable to expect that blood pressure and heart rate would steeply rise out of proportion to oxygen consumption. In response to isometric handgrip exercise, there is an increase in cardiac output and preferential redistribution of blood flow to working skeletal muscle that is critically dependent on three mechanisms of autonomic control (central command, baroreflex, and feedback from working muscle). ${ }^{10}{ }^{11}$ It is well established that isometric handgrip exercise causes a disproportionate rise in heart rate compared with oxygen consumption - that is, not linear as with dynamic exercise. ${ }^{12-14}$

Because isometric contractions hinder local blood flow whereas dynamic exercise facilitates circulation, static exercise produces a higher heart rate and blood pressure. ${ }^{15}$ One explanation for the commonly observed heart rate- $\dot{\mathrm{V}}_{2}$ dissociation during climbing is that climbers may stimulate chemical afferents via the so called muscle metaboreflex with repetitive static forearm contractions. The muscle metaboreflex elicits a sympathetically mediated pressor response consisting of increased heart rate, ventricular performance, central blood volume mobilisation and cardiac output, vasoconstriction in renal and inactive skeletal muscle vasculatures, and increased systemic arterial pressure. ${ }^{12-14}$ Another explanation for the higher than expected heart rate during climbing is the effect of arm position. During climbing, the arms are often held above the level of the heart. ${ }^{7}$ Performing arm exercise with the arms above the 
Table 2 Summary of studies that have measured heart rate and oxygen consumption during top rope or lead climbing

\begin{tabular}{|c|c|c|c|c|}
\hline Investigation & Sample size & Climbing grade & Heart rate (beats/min) & $\dot{\mathrm{V}} \mathrm{O}_{2}(\mathrm{ml} / \mathrm{kg} / \mathrm{min})$ \\
\hline \multirow[t]{2}{*}{ Sheel et $a l^{6}$} & 9 & $5.11 \mathrm{c}$ & $144(14)$ & $22.7(3.7)$ \\
\hline & & $5.10 c$ & 129 (13) & 20.1 (3.3) \\
\hline \multirow{3}{*}{ Mermier et $a l^{7}$} & 14 & $5.11+$ & 163 (15) & $24.9(4.9)$ \\
\hline & & 5.9 & 155 (15) & $21.9(5.3)$ \\
\hline & & 5.6 & 142 (19) & $20.7(8.1)$ \\
\hline Watts et $a l^{3}$ & 15 & 5. $12 b$ & $148(16)$ & 24.7 (4.3) \\
\hline \multirow[t]{2}{*}{ Billat et $a l^{5}$} & 4 & $5.12 a$ & 176 (14) & $24.9(1.2)$ \\
\hline & & $5.12 a$ & 159 (14) & $20.6(0.9)$ \\
\hline Booth et al ${ }^{2}$ & 7 & $5.10 d$ & 157 (8) & $32.8(2.0)$ \\
\hline
\end{tabular}

head is associated with greater increases in heart rate than exercise with arms at waist level. ${ }^{16}$ Although the position of the arms can range from being level with the feet to fully extended overhead during climbing, much of the time the arms are at or above the level of the heart, which may explain the increase in heart rate. ${ }^{7}$

"Fear or anticipation of falling may partially explain the disproportionate rise in heart rate relative to $\mathrm{VO}_{2}{ }^{\prime \prime}$

Heart rate can be increased because of psychological stress or anxiety. Fear or anticipation of falling may partially explain the disproportionate rise in heart rate relative to $\dot{\mathrm{V}}_{2}{ }^{7}$ In a unique investigation, Williams et $a l^{17}$ concluded that

"...[climbing] represents more of an anxiety-type of psychological stress than a physical stress and as such is probably to increases moral fibre rather than muscle fibre."

Based on more recent data with experienced climbers (see above), coupled with the observations of Williams et al, a more balanced view would suggest that the rise in heart rate is probably due primarily to physiological factors with a smaller contribution from the psychological domain. However, it may be that differences exist in the heart rate response to climbing and falling between the novice and highly skilled climber.

Blood pressure has not been directly measured during climbing, although there is reason to suspect that climbers have a different blood pressure response to arm exercise from non-climbers. Ferguson and Brown ${ }^{18}$ showed an attenuated blood pressure response to isometric handgrip exercise in

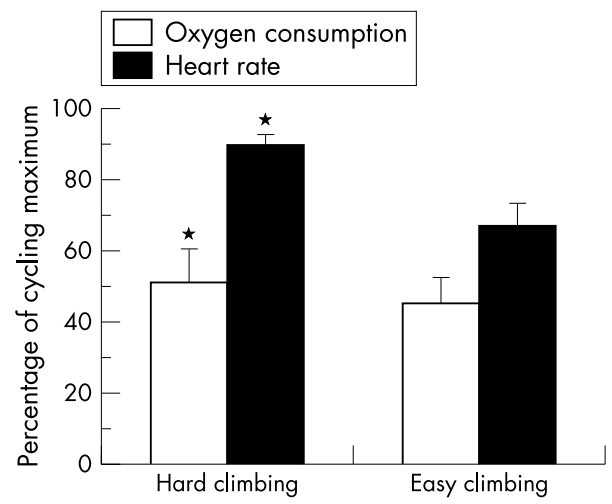

Figure 1 Heart rate and oxygen consumption expressed as percentage of cycling maximum. Values are means (SD) *Significantly higher than easy climbing $(p<0.05)$. Figure taken, with permission, from Sheel et al. ${ }^{6}$ trained climbers compared with untrained subjects. Enhanced forearm vasodilator capacity was also reported. The reduction in blood pressure may have been caused by a desensitisation of afferent fibres or by a reduced build up of metabolites, which would cause less stimulation of the muscle metaboreflex and the coincident rise in systemic arterial pressure. On the basis of these findings, it appears likely that the muscle metaboreflex is active during climbing and that specific rock climbing training probably enhances this system.

\section{Blood lactate}

Several investigations have measured blood lactate immediately after climbing or during a period of recovery. ${ }^{2-5} 78$ Immediately after climbing, blood lactate ranges from 2.4 to $6.1 \mathrm{mmol} / \mathrm{l}$. The relatively large range of reported values is probably because different investigations have used a variety of climbing modes-that is, sport climbing $v$ climbing treadmill-different climbing terrain-that is, size of holds, steepness of terrain, length of climbing route-and different skill levels of climbers. Figure 2 summarises lactate values at rest and after sport climbing or climbing on a climbing treadmill.

When climbers are at, or near, their maximum ability, what is the maximal lactate accumulation? This question was addressed by Watts et al, ${ }^{3}$ who measured blood lactate one minute after climbing where subjects were lead climbing at their maximum ability (climbing grade $=5.12 \mathrm{~b}$; YDS) and where four subjects fell and were unable to complete the climbing route. Lactate concentration was 2.5 (1.6) $\mathrm{mmol} / \mathrm{l}$ before the climb and 5.7 (1.7) $\mathrm{mmol} / \mathrm{l}$ after the climb. These values agree with the findings of Billat et al $5.75(0.95)$ and $4.30(0.77) \mathrm{mmol} / \mathrm{l}$ after two difficult climbing routes. Climbers in this investigation were also climbing nearmaximally (7b; French system). An additional consideration is that during lead climbing, climbers clip a safety rope through a succession of bolt anchors along the route, which

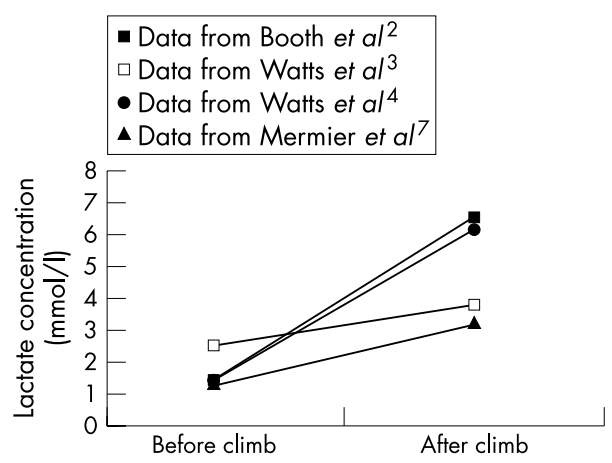

Figure 2 Mean values for blood lactate at rest and after climbing. 
requires additional muscular contraction compared with top rope climbing and may result in greater lactate production. However, no data are available to confirm this speculation. When climbers ascend less demanding terrain, there appears to be less accumulation of lactate. Mermier et al measured blood lactate two minutes after climbing "easy", "moderate", and "hard" routes (5.6, 5.9, and 5.11+ respectively; YDS) where values were $1.64,2.40$, and $3.20 \mathrm{mmol} / \mathrm{l}$.

It appears that when climbers are at their maximal climbing ability, blood lactate is about $5 \mathrm{mmol} / \mathrm{l}$. However, a cautious approach should be taken when interpreting these results. Most climbing studies have used different climbing intensities or subjects with variable climbing experience/skill levels. Despite this caveat, it is reasonable to conclude that a significant accumulation of blood lactate coincides with climbing, and it increases with climbing difficulty. It should be noted that blood lactate concentrations are lower with climbing than with activities such as running or cycling. This is probably because a smaller active muscle mass is producing lactate. From an applied exercise physiology point of view, the increase in blood lactate with increasing difficulty probably has implications for competitive climbers. Because climbing competitions often involve sections of overhanging terrain, the ability to tolerate blood lactate accumulation could be of importance. ${ }^{8}$ Training regimens that optimise this relation would probably be of benefit to the climbing athlete. The ability to recover from a given climb may also be important to competitive climbers, as competitions require the ascent of multiple climbing routes over the course of several hours. Blood lactate concentrations can remain raised for up to 20 minutes after a climb. ${ }^{4}$ To date, only one investigation has attempted to manipulate recovery strategies and determine the effect on blood lactate. Watts et al had subjects climb near-maximally and then perform either passive recovery or active recovery (recumbent leg cycling at $25 \mathrm{~W}$ for 10 minutes). Active recovery caused blood lactate to return to baseline values more quickly than passive recovery. This is a well documented phenomenon that occurs after lower limb exercise, ${ }^{19}$ which appears to hold true for climbing.

\section{Muscular fatigue}

Muscular fatigue is often defined as an exercise induced decline in the capacity of muscle to exert its maximum force. ${ }^{20}$ The physiological mechanisms responsible for muscular fatigue are beyond the scope of this review but can generally be classified as either "central" or "peripheral". A variety of experimental approaches have been used to quantify each type of fatigue. Investigations that have attempted to quantify muscular fatigue after climbing have been limited to measures of maximal voluntary contraction of the forearm musculature by hand grip dynamometry. Studies that have measured handgrip maximal voluntary contraction have produced equivocal results. Watts et al found that handgrip strength decreased 22\% after lead climbing and continued to be lower than resting values 20 minutes after the climb. It was also shown that handgrip endurance was only $57 \%$ of resting values immediately after climbing. Conversely, a separate investigation failed to detect any change in handgrip strength (51.7 (7.5) kg before $v 48.4$ (8.4) $\mathrm{kg}$ after). ${ }^{3}$

The activity of the flexor digitorum superficialis and brachioradialis muscles, measured by integrated electromyography, has been reported to be high during hanging using four fingers of each hand and pull ups to maximum elbow flexion. ${ }^{21}$ The increased recruitment of motor units during climbing-type activities such as these suggests that the forearm musculature may be predisposed to developing fatigue. However, an important consideration is that, although the above laboratory measures may allow quantification of muscle activity, they do not replicate climbing per se. Clearly, additional studies are required to elucidate any climbing-fatigue relation.

\section{PHYSICAL CHARACTERISTICS OF CLIMBERS AND CORRELATES OF PERFORMANCE}

Several studies have measured anthropometric variables in elite climbers and recreational climbers. Semifinalists for a World Cup sport climbing competition (21 men; 18 women) were characterised as being small in stature with low percentage body fat. ${ }^{22}$ Reported values for percentage body fat are 4-14 for men and 10-20 for women. ${ }^{22-24}$ It appears that successful climbers have lower percentage body fat than nonathletic populations, but they do not differ noticeably from other well conditioned athletic groups. In fact, a recent comparison between experienced climbers, recreational climbers, and non-climbers showed no difference for percentage body fat or sum of skinfolds. ${ }^{1}$ Anecdotally, it is widely held in the climbing community that a reduction in body fat can contribute to an improvement in climbing performance. However, it should be stressed that no investigation has shown an improvement in climbing performance with a reduction in percentage body fat. In addition, physical characteristics of climbers such as arm length, leg length, arm span, and the so-called "ape index" (arm span/height) have been measured in climbers but do not appear to be vastly different from control values. ${ }^{124}$ To date, those studies that have sought to measure anthropometric variables and correlate them with indices of climbing performance have been largely descriptive-that is, no climbing specific training interventions or comparison with non-climbing control groups-with relatively small sample sizes. The relation between percentage body fat and other measures of body dimensions with climbing performance has not as yet been clearly established.

Muscular strength has been quantified as hand grip strength and finger strength, and these appear to be higher in elite climbers than recreational and non-climbers. ${ }^{123}$ However, Watts et $a^{22}$ reported that grip strength may not be a necessary attribute of elite climbers. Muscular endurance has been assessed in climbers using a bent arm hang, hand grip endurance test, or pull ups, and elite climbers can typically perform longer bent arm hang manoeuvres, hand grip tests, and more pull ups than their non-climbing counterparts. ${ }^{1}$ Flexibility, as assessed by the sit and reach test, has been reported to be not significantly different between elite climbers, recreational climbers, and nonclimber. ${ }^{1}$ Range of motion, measured at the hip and shoulder, does not appear to relate to climbing ability. ${ }^{24}$

What are the determinants of sport climbing performance? This question was recently addressed by Mermier et al, ${ }^{24}$ who studied 44 climbers (24 men; 20 women) of various skill levels. Variables for each participant included anthropometric measures (height, mass, leg length, percentage body fat), self reported climbing skill and training patterns, and physiological markers (knee and shoulder extension, knee flexion, grip and finger strength, bent arm hang, grip endurance, hip and shoulder flexibility, and upper and lower body anaerobic power). Using a multiple regression analysis, it was shown that training variables explained $58.9 \%$ of the total variance in climbing, whereas the anthropometric and flexibility components explained only $0.3 \%$ and $1.8 \%$ of the total variance. It was concluded that most of the variability in climbing performance can be explained by trainable variables, and climbers do not necessarily need to possess specific anthropometric characteristics to be successful in sport rock climbing. 


\section{SUMMARY}

Rock climbing is unique from a physiological point of view because it requires sustained and intermittent isometric forearm muscle contractions for upward propulsion. During climbing, there are increases in oxygen consumption and heart rate, suggesting that it requires utilisation of a significant portion of whole body aerobic capacity. With increasing climbing difficulty, there is an increased reliance on anaerobic energetic pathways, as evidenced by increases in blood lactate and a disproportionate rise in heart rate in relation to oxygen consumption. The determinants of climbing performance are not clear but may be attributed to trainable variables rather than specific anthropometric characteristics. Ideal training regimens to optimise physiological markers and climbing performance have not been identified. Additional research is needed to assess how specific climbing training impacts on climbing performance.

\section{REFERENCES}

1 Grant S, Hasler T, Davies C, et al. A comparison of the anthropometric, strength, endurance and flexibility characteristics of female elite and recreational climbers and non-climbers. J Sports Sci 2001;19:499-505.

2 Booth J, Marino F, Hill C, et al. Energy cost of sport rock climbing in elite performers. Br J Sports Med 1999;33:14-18.

3 Watts PB, Daggett M, Gallagher P, et al. Metabolic response during sport rock climbing and the effects of active versus passive recovery. Int J Sports Med 2000;21:185-90.

4 Watts PB, Newbury V, Sulentic J. Acute changes in handgrip strength, endurance, and blood lactate with sustained sport rock climbing. J Sports Med Phys Fitness 1996;36:255-60.

5 Billat V, Palleja P, Charlaix T, et al. Energy specificity of rock climbing and aerobic capacity in competitive sport rock climbers. J Sports Med Phys Fitness 1995;35:20-4.

6 Sheel AW, Seddon N, Knight A, et al. Physiological responses to indoor rockclimbing and their relationship to maximal cycle ergometry. Med Sci Sports Exerc 2003;35:1225-31.

7 Mermier CM, Robergs RA, McMinn SM, et al. Energy expenditure and physiological responses during indoor rock climbing. $\mathrm{Br} J$ Sports Med 1997;31:224-8.

8 Watts PB, Drobish KM. Physiological responses to simulated rock climbing at different angles. Med Sci Sports Exerc 1998;30:1118-22.
9 Janot JM, Steffen JP, Porcari JP, et al. Heart rate responses and perceived exertion for beginner and recreational sport climbers during indoor climbing Journal of Exercise Physiology Online 2000;3:1-7.

10 Kaufman MP, Forster HV. Reflexes controlling circulatory, ventilatory and airway responses to exercise. In: Rowell LB, Shepard JT, eds. Exercise: regulation and integration of multiple systems. Oxford: Oxford University Press, 1996:381-442.

11 Rowell LB. Arterial baroreflexes, central command, and muscle chemoreflexes: a synthesis. In: Human cardiovascular control. Oxford: Oxford University Press, 1993:441-83.

12 Rowell LB, O'Leary DS, Kellogg DU. Integration of cardiovascular control systems in dynamic exercise. In: Rowell LB, Shepherd J, eds. Exercise: regulation and integration of multiple systems. Oxford: Oxford University Press, 1996:770-838.

13 O'Leary DS, Augustyniak RA, Ansorge EJ, et al. Muscle metaboreflex improves $\mathrm{O}_{2}$ delivery to ischemic active skeletal muscle. Am J Physiol 1999;276:H1399-403.

14 O'Leary DS, Robinson ED, Butler JL. Is active skeletal muscle functionally vasoconstricted during dynamic exercise in conscious dogs? Am J Physiol 1997;272:R386-91

15 Astrand PO, Rodahl K, Dahl HA, et al. Textbook of work physiology. 4th ed. Champaign, IL: Human Kinetics, 2003.

16 Astrand I, Guharay A, Wahren J. Circulatory responses to arm exercise with different arm positions. J Appl Physiol 1968;25:528-32.

17 Williams ES, Taggart P, Carruthers M. Rock climbing: observations on heart rate and plasma catecholamine concentrations and the influence of oxprenolol. Br J Sports Med 1978;12:125-8.

18 Ferguson RA, Brown MD. Arterial blood pressure and forearm vascular conductance responses to sustained and rhythmic isometric exercise and arterial occlusion in trained rock climbers and untrained sedentary subjects. Eur J Appl Physiol Occup Physiol 1997;76:174-80.

19 McArdle WD, Katch Fl, Katch VL. Exercise physiology: energy, nutrition, and human performance. 5th ed. Baltimore, MD: Lippincott, Williams and Wilkins, 2001

20 Gandevia SC, Enoka RM, McComas AJ, et al. Fatigue: neural and muscular mechanisms. New York: Plenum Press, 1995.

21 Koukoubis TD, Cooper LW, Glisson RR, et al. An electromyographic study of arm muscles during climbing. Knee Surg Sports Traumatol Arthrosc 1995:3:121-4.

22 Watts PB, Martin DT, Durtschi S. Anthropometric profiles of elite male and female competitive sport rock climbers. J Sports Sci 1993;11:113-7.

23 Grant S, Hynes V, Whittaker A, et al. Anthropometric, strength, endurance and flexibility characteristics of elite and recreational climbers. J Sports Sci 1996; 14:301-9.

24 Mermier CM, Janot JM, Parker DL, et al. Physiological and anthropometric determinants of sport climbing performance. Br J Sports Med 2000;34:359-65; discussion 366. 